\title{
A GUERRA DOS CAMPONESES: a mediação de Lutero em discussão
}

TarcísioVanderlinde ${ }^{1}$

Resumo: O artigo tem a finalidade de discutir a mediação desencadeada pelo Reformador Martinho Lutero durante o conflito conhecido como a Guerra dos Camponeses na Alemanha do século XVI e suas repercussões no tempo presente. Na época, a atuação de Lutero demonstrou “radicalidade” em relação a concepções teológicas difundidas pela Igreja Romana, o que faz surgir na Alemanha uma nova Igreja, mais tarde conhecida como Luterana. Paralelamente eclode na região um levante camponês cuja liderança mais destacada foi a do teólogo Thomas Müntzer. Com um relacionamento inicialmente amistoso, os dois líderes espirituais acabaram se afastando por divergências políticas e teológicas.

Palavras - chave: Lutero; Mediação; Guerra dos Camponeses

\begin{abstract}
The purpose of this article is to discuss the mediation unleashed by the Reformer Martin Luther during the conflict known as the Peasants War in XVI century Germany and its repercussions in the present time. At the time, the performance of Luther demonstrated "radicalism" in relation to the theological conceptions spread out by the Roman Church, which makes arise a new church in Germany, later known as the Lutheran Church. In parallel

\footnotetext{
${ }^{1}$ Geógrafo e Historiador. Doutor em história pela UFF. Professor adjunto da Unioeste lotado no Centro de Ciências Humanas Educação e Letras - CCHEL, Campus de Marechal Cândido Rondon, PR.. Integra grupo de pesquisa "Cultura, Fronteiras e Desenvolvimento Regional"/CNPq. Linha de pesquisa: "Identidades e Migrações". Desenvolve pesquisa intitulada "Camponeses/colonos: aspectos da representação local". No que tange às concepções de "mediação", o artigo em pauta se relaciona com a pesquisa em curso. Endereço do autor: Rua 7 de setembro, 3373. 85960-000 M.C.Rondon PR. Fone (45)3254-3985. ebenezer@,certto.com.br ou tarcisio@unioeste.br
} 
to that a peasant revolt breaks out in the region, mainly under the leadership of the theologian Thomas Mûntzer. Although their relationship had been close at the beginning, the two spiritual leaders ended up separated by theological and political divergences.

Keywords: Luther; Mediation; Peasants War

No contexto que revela os antecedentes da Guerra dos Camponeses, as reivindicações camponesas haviam sido expressas em um documento conhecido na historiografia como os “Doze artigos do campesinato da Suábia”, e, segundo fontes traduzidas e disponibilizadas para a atualidade, Lutero teria tido conhecimento do documento e sondado para a mediação do conflito que eclodiria entre os nobres e os camponeses. As fontes não só revelam que de fato Lutero atuou como mediador, mas numa suposta atitude de imparcialidade teria tido um procedimento ambíguo diante do episódio. Tendo como referência, uma análise sobre o assunto, realizada por Romeu R. Martini ${ }^{2}$, este artigo procura discutir a “controvertida” atuação mediadora de Lutero no conflito.

No que tange às concepções sobre mediação, o artigo é iluminado por discussões sistematizadas anteriormente em dissertação de mestrado e tese de doutorado envolvendo questões luteranas no que se refere a formas de inserção daquela Igreja na problemática agrária no Brasil. Conforme se discutiu nas pesquisas, a inserção daquela Igreja acusa a construção de uma identidade peculiar em relação ao contexto social brasileiro. Da sua ação no campo pode ser percebido uma forma de atuar, que se identifica com um "jeito cultural luterano” de realizar a mediação. O surgimento do Centro de Apoio ao Pequeno Agricultor Capa, no seio da Igreja luterana nos anos 70 do século passado, sob este aspecto, pode ser

${ }^{2}$ MARTINI, Romeu R. Lutero e a questão camponesa. In: MARTINI, Romeu R.; GROSS, Eduardo. Movimento da Reforma e contexto latino-americano. São Leopoldo: IEPG, 1993. p. 5. 
considerado sintomático. A reflexão, contudo não se fixa na análise do surgimento do Capa, objeto já discutido por este autor durante fase de realização de mestrado e doutorado e disponibilizado em alguns artigos posteriores. ${ }^{3}$ A atenção, agora, se volta aos aspectos teóricos relacionados à mediação.

A mediação pode ser considerada uma atividade relevante nos processos que se identificam com movimentos sociais. São as lideranças dos movimentos que via de regra representam a mediação. A mediação tem sido estuda por alguns autores atentos aos aspectos institucionais da ação e aos procedimentos metodológicos relacionados ao assunto. A subjetividade parece ser um procedimento que se materializa com freqüência nos processos de mediação. As relações tensas inerentes ao exercício da mediação devem suas causas a vários fatores específicos a cada situação concreta. O tipo de relação entre mediado e mediador é estruturalmente contraditório num processo que deve ser constantemente gerido uma vez que apresenta dificuldades para sua superação. Esta perspectiva permite a compreensão da subjetividade do processo e impõe ao pesquisador a busca de novas crenças e dos novos conteúdos que acompanham o silêncio dos mediados e dos meios como os mediadores lidam

\footnotetext{
${ }^{3}$ A dissertação de mestrado e a tese de doutorado denominam-se respectivamente: "Estratégias de Vida: Agricultura familiar e formas associativas: um estudo de caso - Capa - núcleo oeste" e "Entre Dois Reinos: a inserção luterana entre pequenos agricultores no sul do Brasil’. Os textos procuram historicizar e avaliar a mediação luterana entre os pequenos agricultores no sul do Brasil. Na experiência luterana de inserção no campo, surge em 1978, o Centro de Apoio ao Pequeno Agricultor - Capa, no Estado do Rio Grande do Sul, que, posteriormente expande seu trabalho mediador para os Estados de Santa Catarina e Paraná. A mediação exercida por esta entidade representa interesses eclesiásticos luteranos e é voltada preferencialmente para pequenos agricultores que se dedicam a agroecologia. É oportuno destacar que o Capa apesar de se identificar com um “jeito cultural luterano" de atuar, não faz acepção cultural ou teológica de pessoas. Cf. VANDERLINDE, Tarcísio. Capa: o jeito luterano de atuar com os pequenos agricultores no sul do Brasil. Tempos Históricos. v. 7, n. 1. Marechal Cândido Rondon: Gráfica Líder, 2005.
} 
com os enigmas. O pesquisador não pode se iludir com a verbalização das intencionalidades devendo orientar a coleta de dados para os significados das tensões e querelas, das acusações e das idealizações, o que elas dizem e para que fins são dramatizados como questões fundamentais à expressão das relações que se constroem. Nem sempre as condições de realização da pesquisa acabam sendo as desejadas para o seu melhor desdobramento, levando o pesquisador, por motivos diversos, a adequar-se aos ritmos da dinâmica da relação que estuda. É por isso que importa a consciência desses constrangimentos e os efeitos em termos de compreensão alcançada. Da percepção, o pesquisador pode fazer aparecer dimensões importantes da relação ou modos singulares do exercício da dominação. Delma Pessanha Neves revela os aspectos sutis e contraditórios que costumam ocorrer nos processos de mediação. Sua atenção se volta para os assentamentos agrários da contemporaneidade no Brasil.

O discurso dos mediadores sobre os assentados revela os efeitos do silêncio assumido ou incorporado. A qualificação negativa é recorrente, embora os conteúdos valorizados variem conforme os contextos e os momentos do processo. A ausência é o atributo comum: falta de consciência política, falta de recursos materiais, falta de organização social. Contudo, boa parte destes atributos faz revelar a avaliação dos comportamentos e das atitudes decorrentes da resistência, da reordenação ou do distanciamento frente ao modelo proposto. Faz aparecer a constituição do assentado como uma das forças sociais, exercício possível pela contraposição ao projeto das instituições. Por isso, aqueles atributos dizem respeito aos comportamentos indesejados, compreendidos pelo julgamento moral e por uma nova desqualificação. Se de início os assentados eram concebidos como injustiçados, inocentes (porque ignorantes), sem consciência política, 
apartados das instituições, ao final eram criticados pela esperteza. O discurso dos mediadores revela, assim, não os modos de ação dos assentados, mas o distanciamento em relação às proposições de adesão plena ao modelo e ao produto social e político por aqueles elaborados. ${ }^{4}$

O estudo dos processos de mediação envolve complexidades múltiplas. Em texto que procura introduzir o movimento da Reforma no contexto latino-americano, Romeu R. Martini ensaia uma ponte entre a questão camponesa em que Lutero se envolveu e o movimento dos sem-terra, além de avaliar o papel mediador de Lutero no conflito. O autor destaca que a visão que se tem dos fatos apresenta uma certa nebulosidade quanto à atuação de Lutero. O que acontece é que houve épocas em que, nas igrejas da Reforma, as perguntas relacionadas às questões sociais eram relegadas a um segundo plano quando não excluídas da agenda da vida cristã. Nas últimas três décadas foi possível, tanto na América Latina como no Brasil, fazer perguntas consideradas difíceis de serem feitas em outras épocas. O que não deixa de ser um perigo na interpretação dos fatos, pois com facilidade se acabam invocando fatos históricos não bem conhecidos e analisados para iluminar situações históricas contemporâneas. Martini conclui que isso teria sido feito pelo luteranismo com Lutero e a questão camponesa. O assunto, na óptica do autor, portanto, é de suma importância, permanece atual e deveria ser tratado com a sensibilidade que merece ${ }^{5}$.

Na conjuntura que envolveu o levante camponês na Alemanha do início do século XVI, pode-se destacar que, entre os participantes do movimento, crescia acentuadamente a resistência ao pagamento de tudo que fosse além do estabelecido pelo “direito divino”, ou

\footnotetext{
${ }^{4}$ NEVES, Delma Pessanha. Assentamento rural: reforma agrária em migalhas. Niterói: EDUFF, 1997. Ainda discutem a mediação autores como Alfio Brandenburg e José de Souza Martins em textos diversos. ${ }^{5}$ MARTINI, op. cit.
} 
seja: o dízimo. Mesmo assim, os camponeses iriam propor no segundo de seus Doze Artigos, que se pagasse o dízimo, mas que o mesmo fosse utilizado para pagar o pastor da comunidade local, para amparar os pobres e para servir de reserva a fim de atender a situações de emergência provocadas por calamidades. Do ponto de vista econômico, o processo de empobrecimento dos camponeses vinha de longe, embora parecesse acelerar-se na nova conjuntura com a transferência de pesados tributos para os príncipes e para Roma. A insatisfação camponesa volta-se, além dos príncipes, também contra o clero e o papado. Lutero, com suas idéias e exigências de reforma, encontrou uma situação histórica abalada, que acabou se exacerbando pelas suas palavras e atitudes. ${ }^{6}$ Em Lutero, os camponeses acabaram inicialmente encontrando um exemplo concreto de um "mediador" furioso, impulsivo, que não se calava mais, atitude que já podia ser observada nos primeiros anos de sua atuação ainda como monge ligado à Igreja Romana. ${ }^{7}$

Longe de parecer ser uma postura ambígua, com relação às outras atitudes de Lutero, a nobreza e os príncipes foram duramente criticados pelo Reformador. O seu escrito “A nobreza Cristã da Nação Alemã, acerca da melhoria do estamento cristão”, de 1520, mostrou qual seria o ministério e a função cristã da autoridade. Já no texto “Da autoridade secular”, que data de 1523, Lutero aprofunda seus ensinos sobre como a autoridade secular deveria ser utilizada numa conjuntura cristã. Os usos da obediência e da força foram destacados como legítimos por Lutero quando se trata do exercício da autoridade. O texto poderá ser dividido em três partes: a primeira tratando especificamente do direito da autoridade secular a segunda colocando os limites da autoridade e a terceira dissertando sobre o desempenho cristão de seu encargo.

As críticas aos príncipes podem ter influenciado as atitudes posteriores dos camponeses,

\footnotetext{
${ }^{6}$ Idem, p. 7.

${ }^{7}$ Idem, p. 8 .
} 
pois entre elas Lutero havia afirmado que Deus enlouquecera os príncipes, pois pensavam poder fazer e ordenar aos súditos o que imaginassem no tocante a impostos, exigências de trabalhos e castigos. ${ }^{8}$ No seu escrito "Exortação à paz: resposta aos doze artigos do Campesinato da Suábia”, escrito em 1525, Lutero volta a acusar, além dos príncipes e senhores, também os bispos. Lutero afirmava que estes, no exercício da autoridade secular, não faziam outra coisa do que maltratar e extorquir para custear o luxo e altivez, a ponto de o homem comum não poder mais suportar a situação. ${ }^{9}$

No escrito "Sobre a liberdade cristã”, Lutero sustentou que o cristão é livre de tudo e de todos, ao mesmo tempo em que é servo de todos pelo amor. Essa premissa de Lutero seria invocada pelos camponeses, para proclamar sua insatisfação diante do sistema de servidão. ${ }^{10}$ A população, que observava a Igreja romana com olhos críticos, acabou vendo em Lutero não apenas um interlocutor, mas um libertador e nele depositavam esperança. ${ }^{11}$ Lutero, numa atitude de mediador, tentou fazer a ponte entre partes em litígio: Igreja/príncipes - o poder eclesiástico e secular - e a população. Um confronto que se vinha acentuando de longa data. Porém a articulação tentada por Lutero acabou produzindo um resultado inverso: acelerou o confronto, pois sua "mediação", aos olhos da Igreja, acabou sendo interpretada como uma ofensa ao poder estabelecido por Deus e uma deturpação do Evangelho. Já os opositores do papado viram nos discursos de Lutero uma demonstração da coragem de alguém preocupado em resgatar a verdade, a dignidade de um povo, o verdadeiro Evangelho de Cristo e em dar

\footnotetext{
${ }^{8}$ LUTERO, Martinho. Da autoridade secular, até que ponto se lhe deve obediência. In: Obras selecionadas. São Leopoldo: Sinodal, Porto Alegre: Concórdia, 1996. v. 6, p. 79-114.

9 LUTERO, Martinho. Exortação à paz: Resposta aos Doze Artigos do Campesinato da Suábia. In: Obras selecionadas. São Leopoldo: Sinodal, Porto Alegre: Concórdia, 1996. v. 6, p. 304-329.

${ }^{10}$ LUTERO, Martinho. Sobre a liberdade cristã. In: BONI, Luis Alberto de. Escritos seletos de Martinho Lutero, Thomás Müntzer e João Calvino. Petrópolis: Vozes, 2000. p. 45-80.

11 MARTINI, op. cit., p. 9.
} 
um passo concreto rumo ao aniquilamento de abusos históricos. Aos camponeses pareceu ser o momento favorável de dar sua contribuição concreta nesse processo. Os Doze Artigos permitem uma reflexão sobre a conjuntura em que Lutero exerceu a mediação. ${ }^{12}$

Na vereda reflexiva aberta por Friedrich Engels, Martini ressalta que os Doze Artigos no seu conjunto deixam transparecer a heterogeneidade do grupo que reivindicava e sua conseqüente diversidade de interesses. Aos camponeses, juntou-se ainda a oposição plebéia, que se compunha de burgueses arruinados e da massa excluída do direito de cidadania: oficiais, jornaleiros e numerosos representantes do "lumpenproletariat”. Dessa maneira, seria possível concluir que as reivindicações camponesas refletiam a influência de princípios da Reforma de Lutero, entre os quais se destacava o resgate de critérios bíblicos, a proposição de mudanças que amenizassem o sofrimento dos servos e até alguns componentes de uma revolução mais profunda do sistema vigente. ${ }^{13}$

O historiador Peter Burke faz oportunas observações sobre os mediadores no tempo de Lutero. Discute a apreensão da cultura popular no Início da Idade Moderna a partir de documentos originados pelos próprios mediadores. Entre outras questões e problemas, ele avalia a confiabilidade e a exatidão das fontes, “uma presa esquiva” se considerado o século em pauta. Seu texto fala de um mediador que produz documentos e vestígios que servirão de fontes para historiadores de outro tempo. ${ }^{14}$ Há, portanto, uma dupla conotação na concepção de Burke ao se avaliar a função da mediação de Lutero. Além de produzir documentos que se transformaram em fontes de pesquisa, ele mesmo, Lutero, através de suas ações e do mérito dos seus escritos, exerce papel duplo na mediação: produz a fonte e interfere no processo

\footnotetext{
12 Idem, p. 9-10.

${ }^{13}$ Idem, p. 11.

${ }^{14}$ BURKE, Peter. Uma presa esquiva. In: BURKE, Peter. Cultura Popular na Idade Moderna. Rio de Janeiro: Civilização brasileira, 1995, p. 91-112.
} 
histórico.

Lutero não é o único mediador percebido pelos historiadores no tempo em que viveu. Além das observações de Burke, Martini destaca a grande influência recebida pelo movimento camponês que partia de pregadores livres. Eles teriam atuado mesmo antes da Reforma, fora da estrutura católica romana. No tempo da Reforma não estavam necessariamente alinhados ao pensamento de Lutero, embora muitas vezes refletissem aspectos destacados na sua doutrina. De qualquer forma eram pregações que invocavam a autoridade do Evangelho. Um desses pregadores, Baltazar Hubmaier, professor de Bíblia, pregava contra toda autoridade, religiosa ou secular, afirmando que a ninguém se devia qualquer coisa, a não ser exclusivamente o temor de Deus. ${ }^{15}$

Peter Burke destaca que os textos que chegam às mãos do historiador raramente são produzidos diretamente pelos artesãos e camponeses cujo comportamento se tenta reconstruir, o que leva a concluir que não nos aproximamos deles diretamente, mas através de mediadores. ${ }^{16}$ Destaque-se, neste sentido, os sermões dos frades, em particular dos franciscanos, considerados como as fontes mais importantes para a cultura popular na Europa católica. Os frades não raro eram filhos de artesãos e camponeses. Caracterizavam-se como pregadores populares, no sentido em que apelavam deliberadamente para os incultos, e muitas vezes atraíram grandes públicos. Constantemente pregavam ao ar livre, e as pessoas subiam nas árvores ou se assentavam no alto dos telhados para ouvi-los. Baseavam-se na cultura popular do seu tempo e pregavam em estilo coloquial, usando muitos trocadilhos e rimas, gritando e gesticulando, recorrendo a contos populares para ilustrar suas mensagens e compondo canções para serem cantadas pelas suas congregações. Burke observa que os frades eram “anfíbios” ou “biculturais”, homens de universidade e homens de praça ou de mercado.

\footnotetext{
${ }^{15}$ MARTINI, op.cit. p. 9.

${ }^{16}$ BURKE, op. cit., p. 93-94.
} 
Muitas vezes tinham formação em filosofia e teologia e estavam interessados em transmitir em seus sermões pelo menos algum elemento da grande tradição. Burke destaca que não se pode esquecer que os livros que os vendedores ambulantes faziam circular muitas vezes tinham sido escritos por padres, nobres, doutores e advogados, às vezes um século antes. O historiador alerta que existe toda uma cadeia de intermediários entre um texto específico e os camponeses cujas atitudes supostamente vêm nele expressas, e não se pode supor que os camponeses aceitassem passivamente as idéias expressas nos textos, da mesma forma que os espectadores atuais não acreditam em tudo que vêem na televisão ou escutam pelo rádio. ${ }^{17}$ Quanto às reivindicações dos rebeldes durante o levante camponês, vale a observação de que se trata de um documento que sobreviveu de forma confiável, por terem sido impressas na época, para dar publicidade à causa. Como já se observou anteriormente, não se sabe com exatidão, porém, como o documento foi elaborado e se já não veio sendo “montado” há mais tempo com reivindicações que poderiam não estar diretamente relacionadas ao problema do momento. Burke assinala uma observação relevante ao avaliar a origem da liderança nos levantes camponeses. Segundo ele, os líderes dos levantes muitas vezes eram nobres ou padres, fosse porque haviam sido escolhidos para legitimar o movimento, fosse porque os camponeses não tinham experiência em liderança. Ocasionalmente eram sequer voluntários, tendo sido obrigados a assumir o comando. Voluntários ou não, esses homens também eram mediadores, o que cria uma dificuldade para o historiador descobrir o que a massa do movimento realmente achava que estava fazendo. ${ }^{18}$ Como já se afirmou, Burke conclui que a cultura popular dos inícios da Europa Moderna é esquiva e precisa ser abordada por rodeios, recuperada por meios indiretos e interpretada por uma série de analogias, atitudes pedagógicas que ainda não perderam efeito e indicam caminhos ao se avaliar os processos de mediação

\footnotetext{
${ }^{17}$ Idem, p. 95-99.

${ }^{18}$ Idem, p. 102-103.
} 
entre os camponeses na contemporaneidade ${ }^{19}$.

No levante camponês na Alemanha do século XVI, destacaram-se dois personagens que, no papel de mediadores, acabaram em posições antagônicas, influenciando o curso dos acontecimentos: Martinho Lutero e Thomas Müntzer. Como resultado da mediação dos dois personagens é possível concluir que, enquanto a doutrina de Lutero demonstrava apenas sua preocupação com a realidade sofrida dos camponeses e plebeus, Müntzer teria colocado essa realidade de forma explícita sobre o "balcão da vida”. Enquanto Lutero teria dado sugestões sobre como amenizar a exploração que, segundo Martini dependia de uma relativa capacidade de percepção e reflexão da parte dos camponeses, Müntzer teria apresentado um plano prático, imediato, para acabar com o sofrimento infligido ao povo. Esta teria sido a postura que fez com que a simpatia popular fosse mais intensa com a causa de Müntzer. Por mais que Lutero tivesse razão em evitar e condenar o uso da violência para acabar com a violência, sua proximidade com alguns príncipes deixava margem para suspeitar de sua fidelidade à causa popular. $^{20}$

A reflexão de Martini procura analisar as reivindicações do movimento dos sem-terra à luz dos acontecimentos que envolveram Lutero na revolta dos camponeses na Alemanha. De forma cautelar, ele expõe que Lutero foi uma pessoa que, com suas palavras e atitudes, causou impacto em seu contexto social. Ao entrar no mérito de seus “acertos” e “erros”, fica notória sua influência na história contemporânea e o que ocorreu após sua morte. É por isso que especialmente para as igrejas, que são fruto da Reforma - faz-se necessário perguntar pelas possíveis relações que se poderiam estabelecer entre Lutero e a conjuntura histórica do final do século XX no Brasil, por exemplo. Que relação, por exemplo, poderia haver entre Lutero e as reivindicações do Movimento Sem-Terra?

\footnotetext{
${ }^{19}$ Idem, p. 112.

${ }^{20}$ MARTINI, op. cit., p. 15.
} 
Martini assinala que diferentemente da classe camponesa do século XVI, que se caracterizava por uma composição tão heterogênea quanto ainda teria sido a composição da primeira Liga Camponesa do nordeste brasileiro na década de 50, e na qual não se tinha uma discussão mais profunda do projeto que se defendia, nem se conheciam os amigos e muito menos os inimigos da luta, o MST é composto por uma categoria bem específica - mais densa na fase inicial como movimento: são os despossuídos da terra que vagueiam de propriedade em propriedade, vendendo sua força de trabalho em troca de migalhas, subsistindo assim em condições que lhes ceifam a vida precocemente. O que é fundamental, porém, é que apresentam uma profunda consciência dos objetivos, das forças de apoio - mediação - e dos adversários de sua luta. A história demonstra que o acesso à terra não é dado pelas autoridades responsáveis a não ser do jeito delas (destaque do autor). É preciso lutar; é preciso fazer avançar o processo através de impactos. É isso que justifica a ocupação das propriedades. É por isso que, superando a ingenuidade, não aceitando qualquer promessa, o camponês resiste de formas diversas, inclusive provando a capacidade de produção dos camponeses que tiveram acesso à terra, fato que dá autoridade e respaldo às suas lutas. O que a mediação de Lutero teria a ver com isso?

Lutero foi procurado pelos camponeses para servir de mediador entre eles e os príncipes. Seus escritos demonstram sua sensibilidade às reivindicações camponesas, além de alertar os príncipes sobre as conseqüências de sua falta de sensibilidade diante dos reclames dos camponeses. Lutero recuaria ao exigir o aniquilamento dos mesmos camponeses quando o levante se exacerbou. Na visão de Martini, porém - em sua época e contexto - resgatou dois elementos que redirecionaram a concepção de Estado e Igreja que se tinha até então e que permitiriam um relacionamento com os camponeses de hoje.

Em primeiro lugar, destaca-se a distinção entre dois reinos. Assim como Lutero distinguiu os reinos secular e espiritual - embora mantivesse a visão hierárquica da sociedade 
-, do mesmo modo ele reconheceria uma sociedade de classes, na qual o poder "de cima” oprime e na qual a perspectiva reside em alimentar o poder "de baixo". Aos olhos da modernidade e do tempo presente, Lutero poderia ter sido considerado um conservador. Mas se considerado o feudalismo e a hierarquia romana, Lutero pode ser considerado um mediador que pregou a revolução.

Em segundo lugar, destaca-se o papel da Escritura. A vida pessoal de Lutero e seu comportamento como cidadão foram profundamente transformados pela Escritura, pelas descobertas que nela fez. Ele resgatou o lugar da Escritura dentro da Igreja, na vida do cristão. Martini enfatiza que Lutero teve uma enorme capacidade de reler a Bíblia, por isso é possível crer que ele faria uma leitura da Bíblia que levasse em conta o conceito de propriedade defendido pelo capitalismo. A opinião de Martini é que Lutero nos autoriza a questionar o conceito de propriedade que favorece a matança lenta e gradual, mas também violenta, de milhões de camponeses, enquanto a propriedade sacia a sede de lucro de poucos capitalistas. ${ }^{21}$

Numa posição compartilhada com este autor, Martini observa que as posições de Lutero e a Reforma não podem ser linearmente aplicadas à história do campesinato brasileiro no tempo presente. Nos Doze Artigos do campesinato da Suábia não havia sequer a menção de algo que pudesse se assemelhar a uma idéia de reforma agrária. As idéias relacionadas ao uso da terra eram diferentes. Outros conceitos relacionados ao uso da terra só viriam bem mais tarde. A questão agrária em nosso país continua inconclusa. Há uma história sobre a reforma agrária que é contemporânea e peculiar ao Brasil. O que é que poderia ser aproveitado para a realidade do campo no Brasil, considerando os ensinos de Lutero?

O momento histórico é outro, mas é possível destacar princípios que, considerando um processo de mediação, podem ser norteadores numa luta como a dos camponeses vinculados ao MST. Os mesmos princípios, mediados por pastores ou agentes, continuam válidos, 
embora talvez imperfeitos, se consideradas outras formas de inserção no mundo agrário que não se identificam unicamente com as ações dos sem-terra. Entre os princípios defendidos por Lutero para qualquer época, pode ser destacado o da "não-exploração”. Quando Lutero refletiu sobre usura, ficou claro que não somente o juro excessivo, mas também a apropriação e a exploração dos frutos do trabalho alheio causam sofrimento às pessoas. Embora conclamasse os príncipes ao uso da violência contra os camponeses, Lutero os condenou por continuarem com o massacre depois da derrota consumada. A postura, embora entendida por muitos como ambígua, aponta para o “princípio da não violência”, e pode ser utilizado para a condenação das formas violentas praticadas por latifundiários e forças policiais contra os camponeses que reivindicam em princípio por vias não-violentas. O príncipe que insistisse em governar por vias violentas é desqualificado nos escritos de Lutero. Surge daí o "princípio de autoridade” entendido pelo reformador. O dever das autoridades em relação à sociedade era basicamente o de servir aos seus súditos. O “princípio do direito à vida” aparece com todo vigor nos ensinos de Lutero. Segundo ele, pão é tudo o que pertence ao sustento e às necessidades da vida. Segundo Martini, o direito ao pão para todas as pessoas é um critério luterano que se impõe ao direito de propriedade, sendo, conseqüentemente, elemento de apoio à luta ampla que envolve o Movimento dos Sem-Terra, mas que pode também ser aplicado às outras formas de inserção social. ${ }^{22}$

A mediação "bicultural” - concepção Burkeana - de Lutero foi decisiva no sentido de resgatar o lugar da Escritura como palavra de Deus e não apenas como um receituário disponível a qualquer interesse. Iluminou acontecimentos históricos da época, denunciando abusos dos poderes eclesiástico e político e o sofrimento do povo. Lutero viveu num momento histórico de transição e nele suas idéias representaram uma contribuição significativa, o que não o isenta do erro na sua insistência de aniquilar os camponeses. Com a intenção de atenuar

${ }^{22}$ Idem, p. 18. 
a ação de Lutero contra os camponeses, com base nos escritos de Engels, Martini justifica que nem os camponeses, nem qualquer outra categoria, nem o momento histórico estavam “maduros” para as mudanças desejadas ${ }^{23}$. Este sempre vai ser um problema: saber qual o momento adequado para a mudança. Talvez fosse interessante observar nesta discussão um outro princípio apenas entendido parcialmente por Lutero: “quem sabe faz a hora”. Penso que com relação aos aspectos meramente teológicos, Lutero tenha feito a hora sim. O problema foi fazer valer sua "rebeldia” para o mundo secular.

De qualquer forma parece que os princípios defendidos por Lutero e apontados neste artigo, perpassam à história e chegam à contemporaneidade jogando luzes sobre questões sociais no campo e sobre a forma como a Igreja Luterana ou outras entidades mediadoras atuam neles. Mesmo que não se relacione diretamente ao MST, os princípios defendidos por Lutero se constituem em referenciais apropriados por este autor que julga serem eles ainda adequados para analisar o Brasil de hoje.

Este autor compartilha com a orientação expressa por Eric Hobsbawm ${ }^{24}$, que é possível buscar no passado as “ferramentas” necessárias para lidar com a mudança constante. E sem deixar de se preocupar com o distanciamento necessário - nem sempre alcançado - que o autor que pesquisa deve ter em relação às fontes, o grande historiador lembra que historiadores têm direito de idearem um “futuro desejável” para a humanidade. Na opinião deste autor, um motivo legítimo que o levou a discutir os princípios propostos por Lutero e a sua atuação como mediador para lidar com as problemáticas sociais do tempo presente.

\footnotetext{
${ }^{23}$ Idem, p. 19.

${ }^{24}$ HOBSBAWM, Eric. Sobre a história. São Paulo: Companhia das Letras, 1998.
} 
Bibliografia

BURKE, Peter. Uma presa esquiva. In: BURKE, Peter. Cultura Popular na Idade Moderna. Rio de Janeiro: Civilização brasileira, 1995.

HOBSBAWM, Eric. Sobre a história. São Paulo: Companhia das Letras, 1998.

LUTERO, Martinho. Da autoridade secular, até que ponto se lhe deve obediência. In: Obras selecionadas. São Leopoldo: Sinodal, Porto Alegre: Concórdia, 1996. v. 6, p. 79-114.

LUTERO, Martinho. Exortação à paz: Resposta aos Doze Artigos do Campesinato da Suábia. In: Obras selecionadas. São Leopoldo: Sinodal, Porto Alegre: Concórdia, 1996. v. 6, p. 304-329.

LUTERO, Martinho. Sobre a liberdade cristã. In: BONI, Luis Alberto de. Escritos seletos de Martinho Lutero, Thomás Müntzer e João Calvino. Petrópolis: Vozes, 2000.

MARTINI, Romeu R. Lutero e a questão camponesa. In: MARTINI, Romeu R.; GROSS, Eduardo. Movimento da Reforma e contexto latino-americano. São Leopoldo: IEPG, 1993. NEVES, Delma Pessanha. Assentamento rural: reforma agrária em migalhas. Niterói: EDUFF, 1997.

VANDERLINDE, Tarcísio. Capa: o jeito luterano de atuar com os pequenos agricultores no sul do Brasil. Tempos Históricos. v. 7, n. 1. Marechal Cândido Rondon: Gráfica Líder, 2005. VANDERLINDE, Tarcísio. Entre dois reinos: a inserção luterana entre os pequenos agricultores no sul do Brasil. Cascavel: Edunioeste, 2006.

VANDERLINDE, Tarcísio. Estratégias de vida, agricultura familiar e formas associativistas: um estudo de caso - Capa - núcleo oeste. Dissertação (Mestrado em História) - UFF, Niterói, 2002. 